\title{
Sulphate conjugation of $\beta_{2}$-adrenoceptor stimulating drugs by platelet and placental phenol sulphotransferase
}

\author{
R. J. SODHA \& H. SCHNEIDER \\ Division of Perinatal Physiology, Department of Obstetrics, University Hospital, Frauenklinikstrasse 10,8091 \\ Zurich. Switzerland
}

A possible route of metabolism of $\beta$-adrenoceptor stimulating drugs used in obstetrics consists of conjugation by the enzyme phenol sulphotransferase. The substrate specificities of the platelet and the placental enzymes towards these drugs were tested. The specific activities of the $\beta$-adrenoceptor agonists were found to be relatively similar to those obtained with the catecholamine dopamine but their $K_{m}$ values were considerably higher.

Keywords $\beta$-adrenoceptor agonists sulphoconjugation platelet placenta

\section{Introduction}

The $\beta$-adrenoceptor agonists commonly used to treat premature labour are either catechol derivatives e.g. salbutamol, hexoprenaline and ritodrine or resorcinol derivatives such as fenoterol. They are resistant towards the actions of monoamine oxidase (MAO) and catechol-omethyl transferase (COMT) (Persson \& Persson, 1972). The exception is hexoprenaline which has been shown to undergo $o$-methylation in rat (Kamper et al., 1972). The only remaining route of metabolism consists of conjugation with sulphuric or glucuronic acids. Conjugation to inactive sulphate esters is an important pathway in the metabolism and excretion of catecholamines and many phenolic compounds (Williams, 1959). The enzyme responsible is $3^{\prime}$ phospho adenyl sulphate phenol sulphotransferase (PST, EC 2.8.2.1). It is a cytoplasmic enzyme which serves to transfer the sulphate group from $3^{\prime}$ phospho adenosine $5^{\prime}$ phospho sulphate (PAPS) to various catechol and phenolic compounds. The enzyme has been well characterised in human platelet (Rein et al., 1981) and human placenta (Sodha et al., 1983) where the activity was found to be similar to that in the platelet. We report in the present communication substrate specificities of platelet PST obtained from pregnant and nonpregnant women as well as placental PST towards various $\beta$-adrenoceptor agonists currently used in obstetrics.
It has been reported (Rein et al., 1982) that sulphate conjugation in platelet of phenol and phenolic compounds is selectively inhibited by 2,6 dichloro-4-nitrophenol (DCNP) while sulphation of monoamines and its metabolites remains unaffected. It was postulated that conjugation of phenols and monoamines occurs at two different sites on the same enzyme viz. phenols on Site P and monoamines on Site $\mathbf{M}$. Inhibition studies with DCNP were included in the present set of experiments to determine whether the $\beta$-adrenoceptor agonists act predominantly on any one site.

\section{Methods}

A solution of phospho adenosine $5^{\prime}$ phospho $\left[{ }^{35} \mathrm{~S}\right]$-sulphate ([ $\left.\left.{ }^{35} \mathrm{~S}\right]-\mathrm{PAPS}\right), 1.9-4.2 \mathrm{Ci} / \mathrm{mm}$ in $50 \%$ ethanol was obtained from New England Nuclear, Mass., USA and stored at $-20^{\circ} \mathrm{C}$. Unlabelled PAPS was purchased from PIL Biochemicals, Michigan, USA. 2'6 Dichloro-4- nitro phenol, dopamine and phenol were purchased from Fluka AG, Switzerland and used without further purification. The following were generous gifts: fenoterol $\mathrm{HBr}$ from Boehringer Ingelheim, West Germany; salbutamol sulphate from Glaxo, UK; ritodrine $\mathrm{HCl}$ from Phillip-Duphar, Holland; hexoprenaline $\mathrm{HCl}$, ST 1552 and ST 1553 from Chemie Linz, Austria. 
Platelet enzyme activity from 14 healthy pregnant females between 20 and 32 weeks of gestation was compared with the activity in nine non-pregnant women who were matched for age with the study group. Blood $10 \mathrm{ml}$ from a venous puncture was collected in a polypropylene tube containing $0.5 \mathrm{ml} 5 \%$ ethylene diamine tetra acetic acid (EDTA) and mixed. The platelet enzyme was prepared according to the method of Bonham Carter et al. (1981).

Ten placentae from uncomplicated deliveries after normal pregnancies were also assessed for their PST activity. The preparation of placental PST was similar to that described previously (Sodha et al., 1983). These placentae were not necessarily from the women selected in the previous group.

The enzyme assay was based on that described by Rein et al. (1981). The total incubation mixture of $150 \mu \mathrm{l}$ contained $100 \mu \mathrm{l} 10 \mathrm{~mm}$ phosphate buffer, $\mathrm{pH} 7.4,10 \mu \mathrm{l}$ enzyme suspension and $20 \mu \mathrm{l}$ substrates at various concentrations or $20 \mu \mathrm{l}$ water as blanks. The reaction was started by the addition of $20 \mu \mathrm{l}$ [ $\left.{ }^{35} \mathrm{~S}\right]$-PAPS. The final concentration of PAPS in the incubation mixture was $0.6 \mu \mathrm{M}$. The results are expressed as apparent $K_{m}$ values determined by Lineweaver Burke Plot and the specific activities are expressed as pico moles of product formed $\mathrm{min}^{-1} \mathrm{mg}^{-1}$ protein. The total protein was estimated by the method of Lowry et al. (1951). Where DCNP was included in the assay, $20 \mu$ l of various concentrations of DCNP $\left(10^{-4} M\right.$ to $10^{-8} M$ final concentration in the incubation mixture) were added to the mixture and the substrate activity was expressed as a per cent of that determined in the absence of DCNP.

\section{Results}

The apparent $K_{m}$ values of various $\beta$-adrenoceptor agonists towards PST are shown in Table 1. Salbutamol, ritodrine and fenoterol are similar in their $K_{m}$ values for platelet PST obtained either from pregnant or non-pregnant source. With placental PST, their $K_{m}$ values are only slightly higher. With both platelet and placental enzyme, $K_{m}$ of dopamine and phenol were considerably lower than the $\beta$-adrenoceptor agonists. Hexoprenaline or ST 1553 were not found to be substrates even at very high concentrations but the metabolite ST 1552 gave a particularly low $K_{m}$.

The specific activities of PST towards $\beta$ adrenoceptor agonists were not very different from that of dopamine (Table 2). When $10^{-4} \mathrm{M}$ DCNP was included in the assay, the activity towards only phenol was fully inhibited. Enzyme activity towards salbutamol and ritodrine was reduced by half and towards dopamine and ST 1552 unaffected.

\section{Discussion}

Although the $K_{m}$ values of the $\beta$-adrenoceptor agonists are considerably higher than that of the catecholamine dopamine, the specific activities of this group of drugs are comparable to it. Therefore, the quantity of product formedinactive sulphate esters-with the $\beta$-adrenoceptor agonists and dopamine are similar even though the rates of formation of esters with the $\beta$-adrenoceptor agonists are considerably slower

Table 1 The apparent $K_{m}$ values $(\mu \mathrm{M})$ of $\beta$-adrenoceptor agonists

Values were determined from pooled platelet PST obtained from (i) 14 pregnant women, (ii) nine non-pregnant women and pooled placental PST obtained from (iii) 10 placentae. All compounds were tested in the same assay which was repeated at least twice.

\begin{tabular}{lccc}
\hline Substrate & \multicolumn{2}{c}{$\begin{array}{c}\text { PST } K_{m}(\mu M) \\
\text { Platelet }\end{array}$} & $\begin{array}{c}\text { PST } K_{m}(\mu M) \\
\text { Placental }\end{array}$ \\
\hline Pregnant & Non-pregnant \\
Salbutamol & 66 & 77 & 100 \\
Ritodrine & 47 & 53 & 80 \\
Fenoterol & 51 & 60 & 70 \\
ST 1552 & 2 & 2 & 2 \\
Dopamine & 3 & 2.8 & 3 \\
Phenol & 10 & 9.8 & 10 \\
\hline
\end{tabular}


Table 2 Specific activities of platelet and placental PST and sensitivity to DCNP inhibition

Specific activities (pmol product formed $\mathrm{min}^{-1} \mathrm{mg}^{-1}$ protein) of platelet PST in 14 pregnant and nine non-pregnant women and PST in 10 placentae towards various $\beta$-adrenoceptor agonists. The concentrations of the substrates were twice their respective $K_{m}$ values determined previously. Values are mean \pm s.d.

\begin{tabular}{|c|c|c|c|c|}
\hline \multirow{3}{*}{ Substrate } & \multicolumn{3}{|c|}{ PST specific activity (pmol $\mathrm{min}^{-1} \mathrm{mg}^{-1}$ protein) } & \multirow{3}{*}{$I_{50 \%}$ with $D C N P(M)$} \\
\hline & \multicolumn{2}{|c|}{ Platelet } & \multirow[t]{2}{*}{ Placental } & \\
\hline & Pregnant & Non-pregnant & & \\
\hline Salbutamol & $7.8 \pm 1.9$ & $7.0 \pm 2.4$ & $4.2 \pm 3.2$ & $10^{-4}$ \\
\hline Ritodrine & $11.5 \pm 1.8$ & $11.2 \pm 1.5$ & $5.1 \pm 2.1$ & $10^{-4}$ \\
\hline Fenoterol & $5.7 \pm 0.8$ & $4.7 \pm 0.6$ & $2.6 \pm 0.5$ & $10^{-5}$ \\
\hline ST 1552 & $24.2 \pm 5.4$ & $25.8 \pm 3.5$ & $15.0 \pm 2.2$ & $>10^{-4}$ \\
\hline Dopamine & $18.8 \pm 6.2$ & $17.5 \pm 6.2$ & $14.5 \pm 2.1$ & $>10^{-4}$ \\
\hline Phenol & $5.5 \pm 3.5$ & $5.9 \pm 3.8$ & $4.9 \pm 3.0$ & $10^{-6}$ \\
\hline
\end{tabular}

than with dopamine. Since the compounds were tested together in one assay, a direct comparison is possible. Inability of PST to form sulphate esters of hexoprenaline cannot be explained. It has a double isoprenaline structure and undergoes $o$-methylation on one side to form ST 1553 which was also not a substrate for PST, or omethylation on both sides to form ST 1552 (Kamper et al., 1972) which was a very good substrate for the enzyme indicated by its very low $K_{m}$ and high specific activity. Whether such enzyme kinetics has any clinical relevance is difficult to say. Since the $\beta$-adrenoceptor agonists used to treat premature labour are often administered intravenously, platelet PST may contribute towards their inactivation. Conjugation by placental PST may reduce foetal exposure to free drug.

The fact that at $\mathrm{I}_{50 \%}$ with phenol at DCNP concentration $10^{-6} \mathrm{M}$ no inhibition in the activity of PST towards salbutamol and ritodrine was seen, suggests that these $\beta$-adrenoceptor agonists do not act on $P$ site. At this concentration of DCNP, PST activity towards fenoterol was only slightly suppressed. Therefore, fenoterol is probably a mixed substrate acting on both the $P$ and the $M$ sites.

This work was supported by Schweizerischer Nationalfonds.

\section{References}

Bonham Carter, S. M., Glover, V., Sandler, M., Gillman, P. K. \& Bridges, P. K. (1981). Human platelet phenol sulphotransferase: separate control of the two forms and activity range in depressive illness. Clin. Chim. Acta, 117, 333-344.

Kamper, von B., Leodolter, S., Hellman, G. \& Hertting, G. (1973). Pharmakokinetische Untersuchungen mit $3 \mathrm{H}$-Hexoprenaline an der Ratte. Arzneim. Forsch., 23, 721-729.

Lowry, O. H., Rosebrough, N. J., Farr, A. L. \& Randall, R. J. (1951). Protein measurement with the Folin phenol reagent. J. biol. Chem., 193, 265-273.

Persson, K. \& Persson, K. (1972). The metabolism of terbutaline in vitro by rat and human liver $o$-methyl transferase and monoamine oxidase. Xenobiotica, 2, 375-382.

Rein, G., Glover, V. \& Sandler, M. (1981). Sulphate conjugation of biologically active monoamines and their metabolites by human platelet phenol sulphotransferase. Clin. Chim. Acta, 111, 247-256.

Rein, G., Glover, V. \& Sandler, M. (1982). Multiple forms of phenol sulphotransferase in human tissue: Selective inhibition by dichloronitrophenol. Biochem. Pharmac., 31, 1893-1897.

Sodha, R. J., Glover, V. \& Sandler, M. (1983). Phenol sulphotransferase in human placenta. Biochem. Pharmac., 32, 1655-1657.

Williams, R. T. (1959). Detoxification mechanisms 2nd edition, pp 278-282. New York: Wiley \& Sons.

(Received July 18, 1983, accepted September 20, 1983) 